\title{
Regulatory T cells in systemic lupus erythematosus
}

\author{
Esther Layseca-Espinosa, ${ }^{1,2}$ Adriana Monsiváis-Urenda, ${ }^{1,2}$ Lesly Doníz-Padilla, ${ }^{1,2}$ \\ Haydée Portillo-Salazar, ${ }^{1,2}$ Berenice Hernández-Castro, ${ }^{1,2}$ Marlen Vitales-Noyola ${ }^{3}$ and \\ Roberto González-Amaro ${ }^{1,2}$ \\ ${ }^{1}$ Department of Immunology, Faculty de Medicine; ${ }^{2}$ Center of Research in Health Sciences and Biomedicine; ${ }^{3}$ Endodontics Master's Degree Program, \\ Faculty of Stomatology, Universidad Autónoma de San Luis Potosí, San Luis Potosí, Mexico
}

\begin{abstract}
Systemic lupus erythematosus (SLE) is a chronic autoimmune disease characterized by a loss of tolerance to self-antigens and synthesis of different autoantibodies, with the formation and deposition of immune complexes and damage to multiple organs. $T$ regulatory cells (Tregs) play a crucial role in maintaining peripheral tolerance, controlling the state of activation of the immune system and limiting autoimmune responses. The study of the number and function of the different Treg cell subpopulations in SLE has been the subject of intense research. Depending on the analyzed Treg cell phenotype, the frequency of these cells has been reported to be reduced, increased or unaltered in patients with SLE. In addition, different groups have described that Treg cells suppressive function is reduced or unaffected in patients with SLE. Taken together, the reported data suggest that Treg cells play a relevant role in the pathogenesis of SLE and that these lymphocytes can be considered potential targets for the design of new therapeutic strategies for this condition.
\end{abstract}

KEY WORDS: Immune response regulation. Treg cells. Systemic lupus erythematosus.

\section{Introduction}

Systemic lupus erythematosus (SLE) is a chronic autoimmune disease that is characterized by a loss of tolerance to self-antigens and synthesis of different autoantibodies, with the formation and deposit of immune complexes that cause an inflammatory-necrotic phenomenon in different tissues, mainly the kidney, the skin, blood vessels and the central nervous system. This disease is characterized by multiple immune alterations, including the synthesis of different autoantibodies, B lymphocytes hyperactivity, lymphoid cells increased apoptosis and an increase in IL-10 synthesis. ${ }^{1,2}$ In addition, T lymphocytes of patients with SLE show a decrease in the response to different stimuli in vitro, alterations in cell activation initial phenomena, as well as decreased production and response to IL-2. ${ }^{3}$
$\mathrm{CD}^{+} \mathrm{T}$ lymphocytes, which play a relevant role in SLE pathogenesis, can differentiate into different subpopulations when stimulated by the antigen in the presence of different combinations of cytokines present in the local microenvironment. In this sense, the involvement of an imbalance in the Th1/Th2 responses has been described in the pathogenesis of SLE. ${ }^{4}$ In addition, recent evidence has highlighted the participation of Th17 cells as inflammatory response effectors in this disease. ${ }^{5}$ In this context, IL-17 is able to promote inflammation and tissue damage through the recruitment of neutrophils and monocytes, which facilitates T-lymphocyte tissue infiltration and promotes the production of antibodies.

The loss of tolerance to self-antigens observed in patients with SLE is a consequence of multiple factors, including genetic and environmental factors and alterations in immune response regulation

\section{Correspondence:}

Esther Layseca-Espinosa

E-mail: esther.layseca@uaslp.mx
Date of reception: 29-01-2018

Date of acceptance: 02-08-2018

DOI: 10.24875/GMM.M19000234
Gac Med Mex. 2019;155:68-75

Contents available at PubMed www.gacetamedicademexico.com 
mechanisms. ${ }^{6,7}$ Although most autoreactive T lymphocytes are eliminated in the thymus, the presence of $T$ lymphocytes that recognize self-antigens in peripheral blood and other tissues in healthy individuals is evident. Activation and proliferation of these autoreactive cells is averted by different regulatory mechanisms (immune tolerance), including Treg lymphocytes suppressive effect. However, in certain individuals, autoreactive $T$ cells escape immune response regulation mechanisms control, with their subsequent activation, proliferation and differentiation. Currently, Treg cells are regarded as potential targets for new therapeutic strategies for autoimmune and chronic inflammatory diseases.

\section{Regulatory T cells}

Regulatory $T$ cells play an essential role in the balance between immunity and tolerance. The existence of $\mathrm{T}$ lymphocytes with immunosuppressive function was initially reported more than four decades ago by Gershon and Kondo; however, the first characterization of a subgroup of Treg cells was carried out by Sakaguchi 30 years later. ${ }^{8}$ This lymphocyte subpopulation is composed of $\mathrm{CD} 4^{+} \mathrm{T}$ cells that express interleukin-2 receptor (IL-2) $\alpha$ chain with high intensity (CD25 $\left.5^{\text {high }}\right)$, as well as transcription factor Foxp3. These lymphocytes were initially called natural regulatory $T$ cells (nTreg) because they originate in the thymus as a result of self-antigen recognition and emerge from this organ as fully differentiated cells. nTreg cells mainly recognize their own antigens, but in contrast with effector T lymphocytes, they show limited proliferation capacity in response to activation through the antigen receptor (TCR). In addition, nTreg cells show an important ability to inhibit the activation, proliferation and synthesis of cytokines by effector $T$ lymphocytes. ${ }^{9}$

Recently, nTreg cells were named thymus-derived Treg cells (tTreg), to distinguish them from Foxp3+ Treg cells, which can be generated outside this organ, in peripheral tissues (pTreg), and from those that can be induced in cultures (iTreg) in the presence of TGF- $\beta^{10,11}$ (Figure 1). Regardless of their origin, Treg cells can exert their immunosuppressive activity through different mechanisms, including the synthesis of anti-inflammatory cytokines (TGF- $\beta$, IL-10, IL-35). ${ }^{11}$ In addition to these cells, other lymphocyte subpopulations with regulatory function have been described, including $\mathrm{CD} 9^{+}$Treg cells, a subpopulation of $\mathrm{CD} 4^{+}$ $\mathrm{T}$ cells that apparently emerge from the thymus as fully differentiated cells. These lymphocytes show CD69 constitutive expression, do not express Foxp3 and carry out their suppressing function mainly through the synthesis of IL-10 and TGF- $\beta .^{12,13}$ Different reports indicate that all these Treg cell subpopulations, mainly those that express Foxp3, play an important role in the prevention and pathogenesis of autoimmune diseases, including SLE. ${ }^{14,15}$

\section{Treg cells and SLE}

Since their initial identification, Treg cells became immunologists' focus of attention due to the association between alterations in this cell subpopulation function and the development of autoimmunity. In this regard, Treg cells dysfunction has been implicated in SLE te pathogenesis. ${ }^{16,17}$ However, studies on the number and function of Treg cells in patients with SLE have reported contradictory results. The first investigations carried out in patients with SLE defined Treg cells as $\mathrm{CD} 4^{+} \mathrm{CD} 25^{\text {bright/high }}$ based on initial reports where human Treg cells were described to be located in the $\mathrm{CD} 4^{+} \mathrm{T}$ lymphocyte subpopulation that expresses CD25 with high intensity. As shown in Table 1, several groups have reported a decreased frequency of these cells in patients with SLE,,$^{18,19}$ as well as an inverse correlation between the levels of these cells and the disease activity index (SLEDAI). ${ }^{20,21}$ Conversely, another group found no difference in the frequency of Treg cells between patients with SLE and healthy controls. ${ }^{22}$

The Foxp3 transcription factor is essential for tTreg/ pTreg cells differentiation and function. The importance of this factor has been described both in mice and in humans, where Foxp3 protein lack of expression results in an absence of Treg cells, which leads to fatal effects. Foxp3 expression-deficient mice develop exaggerated $T$ lymphocyte-mediated responses, signs of autoimmunity and eventually die at three or four weeks of age. On the other hand, mutations deriving in FOXP3 gene inactivation in humans are the cause of the IPEX syndrome, characterized by autoimmunity, polyendocrinopathy and enteropathy. Consequently, since the $\mathrm{CD} 4^{+} \mathrm{CD} 25^{\text {+/high }} \mathrm{Foxp} 3^{+}$phenotype appeared to be the best option to identify Treg cells, many groups used this combination of markers to analyze this cell subpopulation and found a reduced percentage or number of these cells in peripheral blood of patients with SLE in comparison with healthy controls, ${ }^{23,24}$ as well as an inverse correlation with the SLEDAI index. ${ }^{23}$ However, several groups 


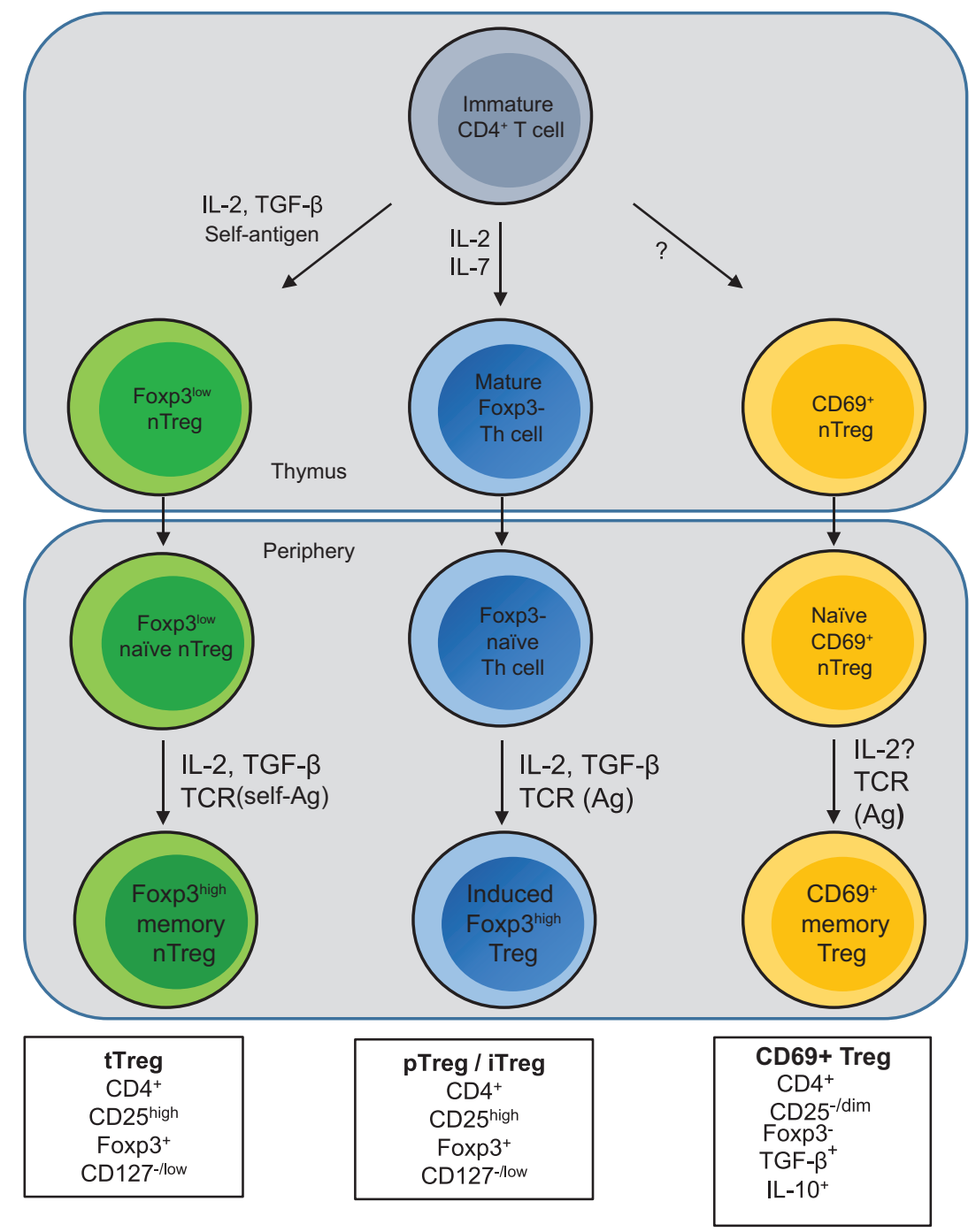

Figure. 1. Differentiation of the main CD4+ T lymphocyte subpopulations. In the thymus, and as a result of IL-2 and TGF- $\beta$ combined effect, differentiation of a subpopulation of immature $C D 4^{+} T$ lymphocytes into Foxp ${ }^{+}$Treg cells takes place. In peripheral lymphoid tissues, these cells are converted into memory cells $\left(C D 45 R O^{+}\right)$through the combined action of cytokines and antigen recognition through TCR. These lymphocytes are called thymus-derived or natural Treg cells (tTreg and nTreg, respectively), because they emerge from the thymus as fully differentiated cells. Conversely, conventional CD4+ Foxp3 naïve Tlymphocytes can be differentiated in an induced manner by the combined action of TCR, IL-2 and TGF- $\beta$ activation in the periphery or in vitro ( $p$ Treg and iTreg, respectively). As indicated, tTreg, $p$ Treg and iTreg cells have the same phenotype and function. In addition, through a process that is not yet well characterized, another subpopulation of $C D 4^{+}$regulatory $T$ cells emerges from the thymus in a fully differentiated form; these lymphocytes are characterized by CD69 constitutive expression and by the absence of Foxp3 (CD69+ Treg). These cells become memory lymphocytes after antigen recognition and, most likely, by the effect of IL-2.

detected increased levels of $\mathrm{CD} 4^{+} \mathrm{CD} 25^{+ \text {thigh }} \mathrm{Foxp} 3^{+}$ cells in these patients ${ }^{25,26}$ and a significant direct correlation with disease activity. ${ }^{26}$ In addition, another study reported not having found differences in the frequency of these cells between patients with SLE and healthy individuals. ${ }^{27}$

Since as a result of cell activation $T$ lymphocytes express CD25 and may show a transient increase in FOXP3 gene expression, the need for additional markers for proper identification of $\mathrm{CD}_{25} 5^{\text {high }} \mathrm{Foxp} 3^{+}$Treg cells became evident. Therefore, since subsequent to
CD127 cell activation (IL-7 receptor $\alpha$ chain) it increases its expression in human naïve $T$ lymphocytes and decreases it in Treg cells, detection of this marker was proposed to likely be useful to discriminate activated T lymphocytes from Treg cells. In this regard, several studies have reported that there are no significant differences in the frequency of $\mathrm{CD} 4^{+} \mathrm{CD} 25^{\text {+high }} \mathrm{Fox}$ $\mathrm{p3}^{+} \mathrm{CD} 127^{\text {-low }}$ cells in peripheral blood of patients with SLE in comparison with healthy controls. ${ }^{25,28}$ However, an additional analysis detected low levels of cells with this phenotype in patients with SLE. ${ }^{29}$ An additional 
Table 1. Treg cell peripheral blood levels in patients with SLE

\begin{tabular}{|c|c|c|c|}
\hline Treg cell subpopulation & Reference & $\begin{array}{l}\text { Treg cell levels in patients with } \\
\text { SLE vs. healthy controls }{ }^{\mathrm{a}}\end{array}$ & $\begin{array}{l}\text { Correlation with } \\
\text { disease activity }^{b}\end{array}$ \\
\hline \multirow[t]{5}{*}{$\mathrm{CD} 4{ }^{+} \mathrm{CD} 25^{\text {brighthigh }}$} & Alvarado-Sánchez et al. ${ }^{22}$ & Equal \% & No \\
\hline & Bonelli et al. ${ }^{20}$ & $\downarrow \%$ & Inverse \\
\hline & Vargas-Rojas et al. ${ }^{18}$ & $\downarrow \%$ & - \\
\hline & Habibagahi et al. ${ }^{21}$ & $\downarrow \%$ : aSLE vs. iSLE and HC & Inverse \\
\hline & Banica et al. ${ }^{19}$ & $\downarrow \%$ & - \\
\hline \multirow[t]{5}{*}{$\mathrm{CD}^{+}{ }^{\mathrm{CD}} 25^{+ \text {high }} \mathrm{Foxp}^{+}$} & Venigalla et al. ${ }^{25}$ & $\uparrow \%$ : aSLE vs. HC; equal number & - \\
\hline & Yan et al..26 & $\uparrow \%$ : aSLE vs. iSLE and HC & Direct \\
\hline & Kleczynska et al.23 & $\downarrow$ number: aSLE vs. iSLE and HC & Inverse \\
\hline & Kim et al. ${ }^{27}$ & Equal \% & - \\
\hline & Margiotta et al. ${ }^{24}$ & $\downarrow(\%)$ & - \\
\hline \multirow[t]{3}{*}{$\mathrm{CD}^{+}{ }^{+} \mathrm{CD} 25^{+ \text {thigh Foxp3+CD127-low }}$} & Venigalla et al. ${ }^{25}$ & Equal \% and number & - \\
\hline & Mesquita et al. ${ }^{28}$ & Equal \% & Direct \\
\hline & Legorreta-Haquet et al. ${ }^{29}$ & $\downarrow(\%)$ & - \\
\hline \multirow{2}{*}{$\begin{array}{l}\text { CD4+CD45RA+Foxp3 } 3^{\text {low }} \text { (rTreg) } \\
\text { CD4+CD45RA-Foxp3 } \\
\text { high } \\
\text { (aTreg) }\end{array}$} & \multirow[t]{2}{*}{ Miyara et al. ${ }^{31}$} & 个\%: aSLE vs. HC & - \\
\hline & & $\downarrow(\%):$ aSLE vs. HC & - \\
\hline CD4+CD45RA+FoxP3 $3^{\text {low }}$ (rTreg) & \multirow[t]{2}{*}{ Pan et al..$^{32}$} & $\uparrow \%$ : aSLE vs. iSLE and HC & Direct \\
\hline & & 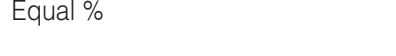 & - \\
\hline \multirow{2}{*}{$\begin{array}{l}\mathrm{CD}^{+}{ }^{+} \mathrm{CD} 25^{++} \mathrm{CD} 45 \mathrm{RA}^{+} \text {(rTreg) } \\
\mathrm{CD}^{+}{ }^{+} \mathrm{CD} 25^{++} \mathrm{CD} 45 \mathrm{RA}^{-} \text {(aTreg) }\end{array}$} & \multirow[t]{2}{*}{ Kim et al. ${ }^{27}$} & Equal \% & - \\
\hline & & Equal \% & - \\
\hline \multirow[t]{2}{*}{$\mathrm{CD}^{+}{ }^{\mathrm{F}}$ oxp3 $^{+}$Helios $^{+}$} & \multirow{2}{*}{$\begin{array}{l}\text { Alexander et al. }{ }^{35} \\
\text { Golding et al. }{ }^{36}\end{array}$} & $\uparrow \%$ & \multirow[t]{2}{*}{ Direct } \\
\hline & & $\uparrow \%:$ Equal number & \\
\hline \multirow{4}{*}{$\begin{array}{l}\mathrm{CD}^{+}{ }^{+} \mathrm{CD} 69^{+} \\
\mathrm{CD} 4^{+} \mathrm{CD} 25^{\text {var }}{ }^{-} \mathrm{C} 69^{+} \mathrm{LAP}+\mathrm{IL}-10^{+} \mathrm{Foxp} 3^{-} \\
\mathrm{CD} 4^{+} \mathrm{NKG} \mathrm{D}^{+} \\
\mathrm{CD} 4^{+} \mathrm{CD} 69^{+} \mathrm{NKG} 2 \mathrm{D}^{+} \mathrm{LAP}^{+} \mathrm{IL}-10^{+} \mathrm{Foxp3}^{-}\end{array}$} & \multirow[t]{4}{*}{ Vitales-Noyola et al. ${ }^{38}$} & $\uparrow \%$ & \multirow[t]{4}{*}{ Direct $^{c}$} \\
\hline & & $\uparrow \%$ & \\
\hline & & $\uparrow \%$ & \\
\hline & & $\uparrow \%$ & \\
\hline
\end{tabular}

tool that has been proposed to differentiate CD25+Foxp3 ${ }^{+}$Treg cells from activated $T$ lymphocytes is FOXP3 gene TSDR region (Treg-specific demethylated region) methylation status analysis..$^{30}$

Additional studies identified different Foxp3 $3^{+}$lymphocyte subpopulations: ${ }^{31}$ CD45RA ${ }^{+}$Foxp3 ${ }^{\text {low }}$ resting Treg cells (rTreg), CD45RA-Foxp3 $3^{\text {high }}$ activated Treg cells (aTreg) and CD45RA-Foxp3 ${ }^{\text {low }}$ non-suppressor $T$ lymphocytes. These cell subpopulations have also been analyzed in SLE, and an increase in the proportion of rTreg cells has been observed in patients with active disease, ${ }^{31,32}$ as well as a decrease in aTreg cell levels. ${ }^{31}$ In one of these studies, the frequency of rTreg cells showed a positive correlation with disease activity and with anti-dsDNA autoantibody levels..$^{32}$ In contrast, another study reported that the levels of these cell subpopulations were comparable to those observed in the controls, but patients with active and inactive SLE were not separately analyzed. ${ }^{27}$

Helios is a member of the Ikaros family of transcription factors, which is preferentially expressed in Treg cells and is able to bind to the FOXP3 gene promoter 
and increase its expression. ${ }^{33}$ Foxp $^{+} \mathrm{Helios}^{+}$Treg cells represent a cell subpopulation with a higher potential to exert a suppressive function ${ }^{34}$ in comparison with Foxp3 ${ }^{+} \mathrm{Helios}^{-}$cells. In addition, $\mathrm{CD}^{+}{ }^{+} \mathrm{Foxp} 3^{+} \mathrm{He}-$ lios $^{+}$cells show a fully demethylated TSDR region. ${ }^{17}$ The analysis of this cell subpopulation reported that the frequency of Foxp3 ${ }^{+}$Helios $^{+}$Treg cells is significantly increased in patients with SLE ${ }^{35,36}$ and that it positively correlates with disease activity. ${ }^{35}$ Similar to what occurs in healthy individuals, Foxp $3^{+} \mathrm{Helios}^{+}$Treg cells of patients with SLE do not synthesize cytokines (IL-2, IFN- $\gamma$ ), possess a fully demethylated TSDR region and express comparable levels of chemokine receptors CXCR3 and CCR4..$^{35}$ In these reports, Foxp3 ${ }^{+} \mathrm{Helios}^{+}$ Treg cells expansion in patients with active SLE were suggested to possibly represent a compensatory mechanism of the autoimmune process.

Another subpopulation of CD4+ Treg lymphocytes, characterized by CD69 constitutive expression, has been described both in humans and in mice. ${ }^{12,13} \mathrm{De}$ tection of $\mathrm{CD} 4{ }^{+} \mathrm{CD} 69^{+} \mathrm{F}$ oxp3-TGF- $\beta^{+}$cells with variable CD25 expression has been reported in peripheral blood and different lymphoid tissues of healthy subjects. ${ }^{37}$ These cells are able to exert a suppressive effect in vitro on autologous effector $T$ lymphocytes activation. ${ }^{37}$ The study of these cells in patients with SLE showed a significant increase in $\mathrm{CD} 4{ }^{+} \mathrm{CD} 25^{\text {var }} \mathrm{C}$ $\mathrm{D}^{2} 9^{+} \mathrm{AP}+\mathrm{IL}-10^{+} \mathrm{Foxp} 3-$ lymphocyte levels in comparison with control individuals. ${ }^{38}$ In addition, a significant decrease in the suppressive effect of these cells on autologous effector lymphocytes was observed in the majority of patients with SLE that were studied. ${ }^{38}$

NKG2D is an activating receptor expressed by most NK cells and by some subpopulations of $T$ lymphocytes. In addition to its functional role in NK cells, $\mathrm{CD}^{+}{ }^{+} \mathrm{NKG} 2 \mathrm{D}^{+} \mathrm{T}$ cells have been reported to be able to exert immunosuppressive activity, which is apparently mediated by the production of TGF- $\beta$ and IL-10. ${ }^{39}$ The levels of CD4+NKG2D+ T cells have been observed to inversely correlate with disease activity in patients with SLE, although the suppressive function of these cells appears to be preserved. ${ }^{39}$ Recently, a variable proportion of $\mathrm{CD}^{+}{ }^{+} \mathrm{CD} 69^{+}$Treg cells has been observed to express NKG2D in healthy individuals, which suggests that $\mathrm{CD} 4^{+} \mathrm{NKG}_{2} \mathrm{D}^{+}$and $\mathrm{CD} 4^{+} \mathrm{CD} 9^{+}$regulatory $T$ cells might correspond to the same subpopulation. ${ }^{37} \mathrm{~A}$ subsequent study revealed that CD4+NKG$2 D^{+}$CD69+LAP+IL-10+Foxp3 lymphocyte levels are higher in patients with SLE in comparison with healthy subjects. ${ }^{38}$ Furthermore, a significant correlation was observed between the percentage of peripheral blood
CD4+NKG2D+ lymphocytes and disease activity or evolution time. ${ }^{38}$ These data suggest that it would be of interest to continue with the characterization of the CD69+NKG2D Treg lymphocyte subpopulation in patients with SLE, as well as to elucidate their possible association with clinical and laboratory parameters. On the other hand, the alterations described in CD69+ Treg cell function in patients with SLE suggest that these cells might have a potential role in the pathogenesis of the inflammatory and autoimmune phenomena observed in this disease.

In addition to the described cells, it is important mentioning the possible role of other lymphocyte subpopulations with regulatory function in the pathogenesis of SLE. Recently, a subpopulation of $\mathrm{CD} 4^{+-}$ Foxp3 ${ }^{+} \mathrm{Bcl}-6^{+} \mathrm{CXCR} 5^{+}$cells, called follicular regulatory T cells (Tfr) was identified, which play an important role in humoral immune response regulation at the germinal centers level. ${ }^{40}$ These cells express the Foxp3 transcription factor and carry out a suppressor function similar to that observed in conventional Treg cells. Tfr cells modulate follicular $T$ helper lymphocytes (Tfh) function, thereby maintaining the balance between immunity and tolerance. ${ }^{40} \mathrm{Tfr}$ cells deregulation may result in the loss of immune tolerance and in a subsequent abnormal production of elevated levels of autoantibodies, which may contribute to the development of autoimmune responses. In this sense, a recent investigation showed the importance of Tfr/Tfh cells activity balance in the autoimmune response observed in the BXD2 murine model, which shows spontaneous formation of self-reactive germinal centers. ${ }^{41}$ In SLE, one study found a reduced number of $\mathrm{CD} 4^{*} \mathrm{CXCR} 5^{\star} \mathrm{FoxP} 3^{*}$ Tfr cells in peripheral blood of newly diagnosed patients; ${ }^{42}$ however, the function of these cells was not evaluated. The potential role of Tfr cells in the pathogenesis of SLE is an interesting topic that needs to be investigated.

\section{Treg cells function in SLE}

In addition to studying Treg cell levels in patients with SLE, it is necessary to analyze their function in order to understand their potential role in the pathogenesis of the disease. Although many studies have reported a decrease in Treg cells suppressor function in patients with SLE in comparison with healthy controls, ${ }^{18,20,22,29,38,43}$ no defects were found in others ${ }^{25,26}$ (Table 2). These discrepancies may be due to differences in cell isolation protocols, to the use of different in vitro stimuli, as well as to the presence or absence 
Table 2. Studies on Treg cells function in patients with SLE

\begin{tabular}{|c|c|c|c|c|}
\hline Treg cell subpopulation & Reference & $\begin{array}{l}\text { Function in } \\
\text { SLE vs. HC }\end{array}$ & $\begin{array}{l}\text { Correlation with } \\
\text { SLE activity }\end{array}$ & Comments \\
\hline $\mathrm{CD}^{+}{ }^{+} \mathrm{CD} 25^{+}$ & Alvarado-Sánchez et al.22 & Reduced & Inverse & - \\
\hline $\mathrm{CD} 4+\mathrm{CD} 25^{\text {bright }}$ & Valencia et al. ${ }^{43}$ & Reduced & - & $\begin{array}{l}\text { Treg cells in vitro activation in patients with SLE } \\
\text { restored their suppressive function }\end{array}$ \\
\hline $\mathrm{CD}^{+}{ }^{+} \mathrm{CD} 25^{+}$ & Yan et al. ${ }^{26}$ & Equal & - & $\begin{array}{l}\text { A reduction in Treg cells function was observed in } \\
\text { patients with aSLE when the assays were carried } \\
\text { out in the presence of IFN-a-producing APCs }\end{array}$ \\
\hline $\mathrm{CD}_{4}{ }^{+} \mathrm{CD} 25^{+}$ & Bonelli et al..$^{20}$ & Reduced & Inverse & - \\
\hline $\mathrm{CD} 4{ }^{+} \mathrm{CD} 25^{\text {high }} \mathrm{CD} 127^{\text {-llow }}$ & Venigalla et al. ${ }^{25}$ & Equal & Inverse & $\begin{array}{l}\text { Effector T cells from patients with aSLE were less } \\
\text { sensitive to autologous and healthy donors' Treg } \\
\text { cells suppressive activity. }\end{array}$ \\
\hline $\mathrm{CD} 4^{+} \mathrm{CD} 25^{+}$ & Vargas-Rojas et al..$^{18}$ & Reduced & - & $\begin{array}{l}\text { Effector T lymphocytes from patients with SLE } \\
\text { were resistant to autologous and allogeneic Treg } \\
\text { cell-mediated suppression. }\end{array}$ \\
\hline $\mathrm{CD}^{+}{ }^{+} \mathrm{CD} 25^{\text {high }} \mathrm{CD} 127^{- \text {-llow }}$ & Legorreta-Haquet et al. ${ }^{29}$ & Reduced & - & - \\
\hline $\mathrm{CD} 4+\mathrm{CD} 45 \mathrm{RA}+\mathrm{CD} 25+$ (rTreg) & Pan et al. ${ }^{32}$ & Reduced & - & - \\
\hline $\mathrm{CD}^{+}{ }^{+} \mathrm{CD}_{69}{ }^{+}$ & Vitales-Noyola et al. ${ }^{38}$ & Reduced & - & $\begin{array}{l}\text { Treg cells inhibited effector T lymphocyte } \\
\text { cytokines activation and production }\end{array}$ \\
\hline
\end{tabular}

of antigen-presenting cells (APCs) in ex vivo functional assays. While some investigations have proposed that the decrease in Treg cells suppressor function in patients with SLE is due to an intrinsic factor, other reports have suggested the participation of extrinsic factors. In this regard, Foxp3 weak expression in Treg cells from patients with SLE has been proposed as an explanation for the poor suppressive function that has been observed in vitro. ${ }^{43}$ Another factor that might participate is IL-2 low production by T lymphocytes in patients with SLE, ${ }^{3,44}$ since this cytokine is essential for Treg cells survival and function. In addition, IFN-D secretion by plasmacytoid dendritic cells of patients with SLE in response to immune complexes has been observed to be able to inhibit Treg cell activity. ${ }^{26,45}$

On the other hand, Treg cells from patients with SLE have been reported to be able to efficiently inhibit B-lymphocyte function in vitro, through a mechanism that requires direct interaction with these cells. ${ }^{46}$

CD4 ${ }^{+}$CD25- effector $T$ lymphocytes from patients with SLE have been proposed to be significantly less sensitive to the suppressive effect of autologous and healthy donors' Treg cells. ${ }^{18,25}$ Although the mechanism by means of which effector $T$ lymphocytes of patients with SLE become resistant to Treg cells suppressive function has not yet been characterized, the possible role of transcription factor STAT-3 activation by IL- 6 has been suggested. ${ }^{47}$ In this regard, IL-6 increased serum levels have been reported in patients with SLE. ${ }^{48}$ In addition, IL- 6 has been observed to exert a synergistic effect with TGF- $\beta$ to induce Th17 lymphocytes polarization, while inhibiting Treg cells differentiation. ${ }^{49}$ Finally, although the precise causes of Treg cell dysfunction in patients with SLE and other autoimmune diseases has not yet been determined, ${ }^{9,10,50}$ the possible transition of these lymphocytes into pro-inflammatory cells (mainly Th1 and Th17 lymphocytes) is a topic of interest, ${ }^{10,51,52}$ since it is a phenomenon that might contribute to the perpetuation of the autoimmune process.

In conclusion, even though contradictory results have been reported regarding the number and function of Treg cells in patients with SLE, taken together, most data suggest that these cells play an important role in the pathogenesis of this disease.

\section{Treg cells as potential therapeutic targets in SLE}

Treg cells have been proposed as a potential therapeutic tool for patients with autoimmune diseases..$^{53}$ The observation that Treg cells in vivo expansion in lupus murine models has been associated with a beneficial effect on disease progression supports this point. ${ }^{54}$ 
Furthermore, the administration of different immunosuppressive drugs that are currently used for the treatment of patients with SLE, such as glucocorticoids, has been described to be associated with a significant increase in the frequency of Treg cells..$^{55} \mathrm{~A}$ similar effect has been observed with some biological agents such as rituximab. ${ }^{56}$ However, the need for additional strategies focused on the restoration of the alterations described in Treg cells of patients with SLE is evident. Currently, various options that include the administration of in vitro-generated Treg cells or their in vivo induction are being investigated. ${ }^{9,57-60}$ Although most of these strategies are still under development, the therapeutic use of Treg cells in SLE remains an interesting possibility to be explored in the near future.

\section{References}

1. Sang A, Zheng YY, Morel L. Contributions of $B$ cells to lupus pathogenesis. Mol Immunol. 2014;62:329-338.

2. Mistry P, Kaplan MJ. Cell death in the pathogenesis of systemic lupus erythematosus and lupus nephritis. Clin Immunol. 2017;185:59-73.

3. Mak A, Kow NY. The pathology of T cells in systemic lupus erythematosus. J Immunol Res. 2014;2014:419029.

4. Talaat RM, Mohamed SF, Bassyouni IH, Raouf AA. Th1/Th2/Th17/Treg cytokine imbalance in systemic lupus erythematosus (SLE) patients: correlation with disease activity. Cytokine. 2015;72:146-153.

5. Martin JC, Baeten DL, Josien R. Emerging role of IL-17 and Th17 cells in systemic lupus erythematosus. Clin Immunol. 2014;154:1-12.

6. Ghodke-Puranik Y, Niewold TB. Immunogenetics of systemic lupus erythematosus: a comprehensive review. J Autoimmun. 2015;64:125-136.

7. Podolska MJ, Biermann MHC, Maueröder C, Hahn J, Hermann M. Inflammatory etiopathogenesis of systemic lupus erythematosus: an update. J Inflamm Res. 2015;8:161-171.

8. Hori S, Takahashi T, Sakaguchi S. Control of autoimmunity by naturally arising regulatory CD4+ T cells. Adv Immunol. 2003;81:331-337.

9. Miyara M, Ito $Y$, Sakaguchi S. Treg-cell therapies for autoimmune rheumatic diseases. Nat Rev Rheumatol. 2014:10:543-551.

10. Sakaguchi S, Vignali DA, Rudensky AY, Niec RE, Waldmann H. The plasticity and stability of regulatory T cells. Nat Rev Immunol. 2013; 13:461-467.

11. Shevach EM, Thornton AM. tTregs, pTregs, and iTregs: similarities and differences. Immunol Rev. 2014;259:88-102.

12. Cortés JR, Sánchez-Díaz R, Bivalente ER, Barreiro O, Lasarte S, Matesanz-Marín A, et al. Maintenance of immune tolerance by Foxp3+ regulatory $\mathrm{T}$ cells requires CD69 expression. J Autoimmun. 2014; 55:51-62.

13. Han Y, Guo Q, Zhang M, Chen Z, Cao X. CD69+ CD4+ CD25- T cells, a new subset of regulatory $T$ cells, suppress $T$ cell proliferation through membrane-bound TGF- $\beta 1$. J Immunol. 2009;182:111-120.

14. González-Amaro R, Marazuela M. T regulatory (Treg) and T helper 17 (Th17) lymphocytes in thyroid autoimmunity. Endocrine. 2016:52:30-38.

15. Miyara M, Gorochov G, Ehrenstein M, Musset L, Sakaguchi S, Amoura Z. Human FoxP3+ regulatory $T$ cells in systemic autoimmune diseases. Autoimmun Rev. 2011:10:744-755.

16. Giang S, La-Cava A. Regulatory T cells in SLE: biology and use in treatment. Curr Rheumatol Rep. 2016;18:67.

17. Ohl K, Tenbrock K. Regulatory T cells in systemic lupus erythematosus. Eur J Immunol. 2015:45:344-355.

18. Vargas-Rojas MI, Crispín JC, Richaud-Patin Y, Alcocer-Varela J. Quantitative and qualitative normal regulatory $T$ cells are not capable of inducing suppression in SLE patients due to T-cell resistance. Lupus. 2008:17:289-294.

19. Banica LM, Besliu AN, Pistol GC, Stavaru C, Vlad V, Predeteanu D, et al. Dysregulation of anergy-related factors involved in regulatory $T$ cells defects in Systemic Lupus Erythematosus patients: Rapamycin and Vitamin $\mathrm{D}$ efficacy in restoring regulatory $\mathrm{T}$ cells. Int $\mathrm{J}$ Rheum Dis. 2016;19:1294-1303.

20. Bonelli M, Savitskaya A, Von Dalwigk K, Steiner CW, Aletaha D, Smolen JS, et al. Quantitative and qualitative deficiencies of regulatory T cells in patients with systemic lupus erythematosus (SLE). Int Immunol. 2008;20:861-868
21. Habibagahi M, Habibagahi Z, Jaberipour M, Aghdashi A. Quantification of regulatory $T$ cells in peripheral blood of patients with systemic lupus erythematosus. Rheumatol Int. 2011;31:1219-1225.

22. Alvarado-Sánchez $B$, Hernández-Castro $B$, Portales-Pérez D, Baranda L, Layseca-Espinosa E, Abud-Mendoza C, et al. Regulatory T cells in patients with systemic lupus erythematosus. J Autoimmun. 200627:110-118.

23. Kleczynska W, Jakiela B, Plutecka H, Milewski M, Sanak M, Musial J. Imbalance between Th17 and regulatory T-cells in systemic lupus erythematosus. Folia Histochem Cytobiol. 2011;49:646-653.

24. Margiotta D, Navarini L, Vadacca M, Basta F, Lo Vullo M, Pignataro F, et al. Relationship between leptin and regulatory $T$ cells in systemic lupus erythematosus: preliminary results. Eur Rev Med Pharmacol Sci. 2016;20:636-641.

25. Venigalla RK, Tretter T, Krienke S, Max R, Eckstein V, Blank N, et al. Reduced CD4+, CD25- T cell sensitivity to the suppressive function of CD4+,CD25high,CD127-/low regulatory $T$ cells in patients with active systemic lupus erythematosus. Arthritis Rheum. 2008:58:2120-2130.

26. Yan $B$, Ye S, Chen G, Kuang M, Shen N, Chen S. Dysfunctional CD4+,CD25+ regulatory $T$ cells in untreated active systemic lupus erythematosus secondary to interferon-alpha-producing antigen-presenting cells. Arthritis Rheum. 2008:58:801-812.

27. Kim JR, Chae JN, Kim SH, Ha JS. Subpopulations of regulatory T cells in rheumatoid arthritis, systemic lupus erythematosus, and Behcet's disease. J Korean Med Sci. 2012;27:1009-1013.

28. Mesquita D, De-Melo-Cruvinel W, Araujo J, Pucci F, Salmazi K, Kallas E, et al. Systemic lupus erythematosus exhibits a dynamic and continuum spectrum of effector/regulatory T cells. Scand J Rheumatol. 2011;40: 41-50.

29. Legorreta-Haquet MV, Chávez-Rueda K, Chávez-Sánchez L, Cervera-Castillo $\mathrm{H}$, Zenteno-Galindo $\mathrm{E}$, Barile-Fabris L, et al. Function of Treg cells decreased in patients with systemic lupus erythematosus due to the effect of prolactin. Medicine (Baltimore). 2016;95:e2384.

30. lizuka-Koga M, Nakatsukasa $H$, Ito M, Akanuma T, Lu Q, Yoshimura A. Induction and maintenance of regulatory $T$ cells by transcription factors and epigenetic modifications. J Autoimmun. 2017:83:113-121.

31. Miyara M, Yoshioka Y, Kitoh A, Shima T, Wing K, Niwa A, et al. Functional delineation and differentiation dynamics of human CD4+ T cells expressing the FoxP3 transcription factor. Immunity. 2009;30:899-911.

32. Pan X, Yuan X, Zheng Y, Wang W, Shan J, Lin F, et al. Increased CD45RA+ FoxP3(low) regulatory $T$ cells with impaired suppressive function in patients with systemic lupus erythematosus. PLoS One. 2012;7: e34662.

33. Grzanka J, Leveson-Gower D, Golab K, Wang XJ, Marek-Trzonkowska N, Krzystyniak A, et al. FoxP3, Helios, and SATB1: roles and relationships in regulatory T cells. Int Immunopharmacol. 2013;16:343-347.

34. Sugita K, Hanakawa S, Honda T, Kondoh G, Miyachi Y, Kabashima K, et al. Generation of Helios reporter mice and an evaluation of the suppressive capacity of Helios(+) regulatory $\mathrm{T}$ cells in vitro. Exp Dermatol. 2015;24:554-556.

35. Alexander T, Sattler A, Templin L, Kohler S, Groß C, Meisel A, et al. Foxp3+ Helios+ regulatory $T$ cells are expanded in active systemic lupus erythematosus. Ann Rheum Dis. 2013:72:1549-1558.

36. Golding A, Hasni S, Illei G, Shevach EM. The percentage of FoxP3+Helios+ Treg cells correlates positively with disease activity in systemic lupus erythematosus. Arthritis Rheum. 2013:65:2898-2906.

37. Vitales-Noyola M, Doníz-Padilla L, Álvarez-Quiroga C, Monsiváis-Urenda A, Portillo-Salazar H, González-Amaro R. Quantitative and functional analysis of CD69+ NKG2D+ T regulatory cells in healthy subjects. Hum Immunol. 2015;76:511-518.

38. Vitales-Noyola M, Oceguera-Maldonado B, Niño-Moreno $P$, Baltazar-Benítez N, Baranda L, Layseca-Espinosa E, et al. Patients with systemic lupus erythematosus show increased levels and defective function of CD69(+) T regulatory cells. Mediators Inflamm. 2017;2017:2513829.

39. Dai Z, Turtle CJ, Booth GC, Riddell SR, Gooley TA, Stevens AM, et al. Normally occurring NKG2D+ CD4+ T cells are immunosuppressive and inversely correlated with disease activity in juvenile-onset lupus. J Exp Med. 2009;206:793-805

40. Zhu Y, Zou L, Liu YC. T follicular helper cells, T follicular regulatory cells and autoimmunity. Int Immunol. 2016;28:173-179.

41. Ding Y, Li J, Yang P, Luo B, Wu Q, Zajac AJ, et al. Interleukin-21 promotes germinal center reaction by skewing the follicular regulatory $T$ cell to follicular helper T cell balance in autoimmune BXD2 mice. Arthritis Rheumatol. 2014:66:2601-2612.

42. Ma L, Zhao $P$, Jiang Z, Shan $Y$, Jiang $Y$. Imbalance of different types of CD4(+) forkhead box protein 3 (FoxP3) (+) T cells in patients with new-onset systemic lupus erythematosus. Clin Exp Immunol. 2013;174:345-355.

43. Valencia X, Yarboro C, Illei G, Lipsky PE. Deficient CD4+CD25high T regulatory cell function in patients with active systemic lupus erythematosus. J Immunol. 2007:178:2579-2588.

44. Humrich JY, Riemekasten G. Restoring regulation-IL-2 therapy in systemic lupus erythematosus. Expert Rev Clin Immunol. 2016;12: $1153-1160$ 
45. Bacher N, Raker V, Hofmann C, Graulich E, Schwenk M, Baumgrass R, et al. Interferon-alpha suppresses cAMP to disarm human regulatory $T$ cells. Cancer Res. 2013;73:5647-5656.

46. Liu Y, Liu A, likuni N, Xu H, Shi FD, La-Cava A. Regulatory CD4+ T cells promote B cell anergy in murine lupus. J Immunol. 2014:192:4069-4073.

47. Lam E, Choi SH, Pareek TK, Kim BG, Letterio JJ. Cyclin-dependent kinase 5 represses Foxp3 gene expression and Treg development through specific phosphorylation of Stat3 at Serine 727. Mol Immunol. 2015;67: 317-324.

48. Abdel Galil SM, Ezzeldin N, El-Boshy ME. The role of serum IL-17 and IL-6 as biomarkers of disease activity and predictors of remission in patients with lupus nephritis. Cytokine. 2015;76:280-287.

49. Jordan SC, Choi J, Kim I, Wu G, Toyoda M, Shin B, et al. Interleukin-6, A cytokine critical to mediation of inflammation, autoimmunity and allograft rejection: therapeutic implications of IL-6 receptor blockade. Transplantation. 2017;101:32-44.

50. Grant CR, Liberla R, Mieli-Vergani G, Vergani D, Longhi MS. Regulatory T-cells in autoimmune diseases: challenges, controversies and-yet-unanswered questions. Autoimmun Rev. 2015:14:105-116.

51. Basu R, Hatton RD, Weaver CT. The Th17 family: flexibility follows function. Immunol Rev. 2013;252:89-103.

52. Annunziato $F$, Cosmi L, Liotta F, Maggi E, Romagnani S. Human helper type 1 dichotomy: origin, phenotype and biological activities. Immunology. 2015;144:343-351.
53. Spence A, Klementowicz JE, Bluestone JA, Tang Q. Targeting Treg signaling for the treatment of autoimmune diseases. Curr Opin Immunol. 2015;37:11-20.

54. Yan JJ, Jambaldorj E, Lee JG, Jang JY, Shim JM, Han M, et al. Granulocyte colony-stimulating factor treatment ameliorates lupus nephritis through the expansion of regulatory T cells. BMC Nephrol. 2016:17:175.

55. Mathian A, Jouenne R, Chader D, Cohen-Aubart F, Haroche J, Fadlallah J, et al. Regulatory $\mathrm{T}$ cell responses to high-dose methylprednisolone in active systemic lupus erythematosus. PLoS One. 2015;10:e0143689.

56. Vigna-Pérez M, Hernández-Castro B, Paredes-Saharopulos $\mathrm{O}$, Portales-Pérez D, Baranda L, Abud-Mendoza C, et al. Clinical and immunological effects of Rituximab in patients with lupus nephritis refractory to conventional therapy: a pilot study. Arthritis Res Ther. 2006;8:R83.

57. Petrillo MG, Ronchetti S, Ricci E, Alunno A, Gerli R, Nocentini G, et al. $\mathrm{GITR}+$ regulatory $\mathrm{T}$ cells in the treatment of autoimmune diseases. Autoimmun Rev. 2015(2);14:117-126.

58. Durcan L, Petri M. Immunomodulators in SLE: clinical evidence and immunologic actions. J Autoimmun. 2016;74:73-84.

59. Wang D, Huang S, Yuan X, Liang J, Xu R, Yao G, et al. The regulation of the Treg/Th17 balance by mesenchymal stem cells in human systemic lupus erythematosus. Cell Mol Immunol. 2017;14:423-431.

60. Miyara M, Chader D, Burlion A, Goldstein J, Sterlin D, Norol F, et al. Combination of IL-2, rapamycin, DNA methyltransferase and histone deacetylase inhibitors for the expansion of human regulatory $\mathrm{T}$ cells. Oncotarget. 2016;8:104733-104444 